\title{
Mineralization of $\mathrm{CaCO}_{3}$ in the Presence of Egg White Lysozyme
}

\author{
Alina E. Voinescu, ${ }^{\dagger}$ Didier Touraud ${ }^{\dagger}$ Alois Lecker, ${ }^{\ddagger}$ Arno Pfitzner, ${ }^{\ddagger}$ Werner Kunz, ${ }^{*}, \dagger$ and \\ Barry W. Ninham ${ }^{\S}$ \\ Institute of Physical and Theoretical Chemistry and Institute of Inorganic Chemistry, University of \\ Regensburg, Germany, and Department of Applied Mathematics, Research School of Physical Sciences, \\ Australian National University, Australia
}

Received June 26, 2007. In Final Form: August 31, 2007

\begin{abstract}
The influence of egg white lysozyme on the size, shape, crystallography, and chemical composition of amorphous calcium carbonate (ACC) particles obtained from aqueous $\mathrm{CaCl}_{2}-$ dimethyl carbonate (DMC) $-\mathrm{NaOH}$ solutions was studied. At the onset of precipitation, the presence of lysozyme led to much smaller particles $(50-400 \mathrm{~nm}$ spherical amorphous lysozyme-calcium carbonate particles (Ly-ACC)) than those obtained from lysozyme-free solution. The nanospheres were in some cases aggregated and in addition embedded in a faint network. Their size and interconnection depended on the concentration of egg white lysozyme. When the Ly-ACC particles were left in contact with the mother liquor $\left(\mathrm{CaCl}_{2} / \mathrm{DMC} / \mathrm{NaOH} / \mathrm{lys}\right.$ sozyme solution) for $24 \mathrm{~h}$, they transformed directly and exclusively into crystalline calcite. The observed results may be of relevance for a better understanding of the role of lysozyme in the process of eggshell mineralization.
\end{abstract}

\section{Introduction}

Lysozyme is a monomeric globular protein with an $\alpha$ helix, $\beta$ sheet and a radius of gyration of $22 \AA$. It contains 129 amino acids, and its isoelectric point is 11.35 . This protein is known to be present in the eggshell matrix, ${ }^{1}$ along with calcium carbonate.

Calcium carbonate is an important biogenic mineral in organisms. It is widely used by nature as an inorganic component in exoskeletons and tissues of many mineralizing organisms, ${ }^{2}$ giving them strength and shape. ${ }^{3}$ It exists in a variety of polymorphic forms: hydrates (i.e., amorphous calcium carbonate (ACC), calcium carbonate monohydrate, and calcium carbonate hexahydrate) and anhydrous (calcite, aragonite, and vaterite) calcium carbonate.

Synthetic ACC contains 0.5 mole of water per formula unit $\left(\mathrm{CaCO}_{3} \cdot 0.5 \mathrm{H}_{2} \mathrm{O}\right)_{.}{ }^{4,5}$ It is thermodynamically and kinetically highly unstable under ambient conditions, and it transforms quickly into one of the anhydrous crystalline phases. ${ }^{6,7}$ Nevertheless, this transformation can be significantly retarded by a substantial level of inorganic and synthetic organic additives within the mineral phase (such as magnesium ${ }^{8,9}$ and triphosphate ${ }^{10}$ ions and hydrophilic blockcopolymers, ${ }^{11}$ poly(propylenimin)

* To whom correspondence should be addressed. Fax: (+) 49941943 4532. E-mail: werner.kunz@chemie.uni-regensburg.de.

Institute of Physical and Theoretical Chemistry, University of Regensburg.

$\doteqdot$ Institute of Inorganic Chemistry, University of Regensburg.

$\S$ Australian National University and Visiting Professor, Regensburg University.

(1) Hincke, M. T.; Gautron, J.; Panhéleux, M.; Garcia-Ruiz, J. M.; McKee, M. D.; Nys, Y. Matrix Biol. 2000, 19, 443.

(2) Mann, S. Biomineralisation: Principles and Concepts in bioinorganic Materials Chemistry; Oxford University Press: Oxford, U.K., 2001.

(3) Weiner, S.; Addadi, L. J. Mater. Chem. 1997, 7, 689

(4) Brecevic, L. J. Cryst. Growth 1989, 98, 504.

(5) Levi-Kalisman, Y.; Raz, S.; Weiner, S.; Addadi, L. Adv. Funct. Mater. 2002, 12,43

(6) Johnson, J.; Merwin, H. E.; Williamson, E. D. Am. J. Sci. 1916, 41, 473

(7) Pantoni, D.; Bolze, J.; Dingenouts, N.; Narayanan, T.; Ballauff, M. J. Phys. Chem. B 2003, 107, 5123.

(8) Loste, E.; Wilson, R. M.; Seshadri, R.; Meldrum, F. C. J. Cryst. Growth 2003, 254, 206

(9) Raz, S.; Weiner, S.; Addadi, L. Adv. Mater. 2000, 12, 38.

(10) Clarkson, J. R.; Price, T. J.; Adams, C. J. J. Chem. Soc., Faraday Trans 1992, 88, 243.

(11) Cölfen, H.; Qi, L. Chem.-Eur. J. 2001, 7, 106. dendrimeres, ${ }^{12,13}$ diphosphate-substituted poly(ethylene glycol),${ }^{14}$ poly(acrylic acid) ${ }^{15}$ polysaccharides, ${ }^{16,17}$ poly(vinyl alcohol), ${ }^{18}$ and polyaspartate, ${ }^{19}$ respectively).

In contrast, a biogenic amorphous precipitate can be stable for a long period of time ${ }^{20}$ because of biological matrices, ${ }^{21}$ which prevent crystallization. Stable ACCs have been reproduced in vitro by adding specific proteins rich in glutamic acid and glutamine, extracted from spicules, ${ }^{22}$ sponges, ${ }^{23}$ and gastroliths of crustaceans. ${ }^{24} \mathrm{ACC}$ also serves as a precursor phase during the formation of other minerals (calcite, aragonite, and vaterite) in the biomineralization process.

Thus, Raz et al. ${ }^{22}$ reported that ACC is the precursor of calcite for the growth of spicules in sea urchin larvae of different species. Recently, Lakshminarayanan et al. ${ }^{25}$ demonstrated the possible formation of the ACC phase in the first stages of precipitation and its subsequent transformation to calcite in quail eggshell biomineralization.

Avian eggshell contains $95 \%$ inorganic calcite crystals along with an organic matrix consisting of three groups: ubiquitous matrix protein including clusterin and osteopontin, the novel eggshell matrix (ovocleidins and ovocalyxins), which is unique to the eggshell calcification process, and egg white proteins. ${ }^{26}$

(12) Donners, J. J. M.; Heywood, B. R.; Meijer, E. W.; Nolte, R. J. M.; Roman, C.; Schenning, A.; Sommerdijk, N. Chem. Commun. 2000, 19, 1937.

(13) Donners, J. M.; Meijer, E. W.; Nolte, R. J. M.; Sommerdijk, N. Polym Mater. Sci. Eng. 2001, 84, 1039.

(14) Kjillin, P.; Holmberg, K.; Nyden, M. Colloids Surf., A 2001, 194, 49. (15) Xu, G.; Yao, N.; Aksay, I. A.; Grove, J. T. J. Am. Chem. Soc. 1998, 120 , 11977

(16) Sugawara, A; Kato, T. Chem. Commun 2000, 6, 487.

(17) Hosoda, N.; Kato, T. Chem. Mater. 2001, 13, 688.

(18) Hosoda, N.; Sugawara, A.; Kato, T. Macromolecules 2003, 36, 6449

(19) Gower, L. A.; Tirrell, D. A. J. Cryst. Growth 1998, 191, 153.

(20) Meldrum, F. C. Int. Mater. Rev. 2003, 48 (3), 187.

(21) Lowenstam, H. A.; Weiner, S. On Biomineralisation; Oxford University Press: New York, 1989.

(22) Raz, S.; Hamilton, P. C.; Wilt, F. H.; Weiner, S.; Addadi, L. Adv. Funct Mater. 2003, 13, 480.

(23) Aizenberg, J.; Lambert, G.; Addadi, L.; Weiner, S. Adv. Mater. 1996, 8 , 222

(24) Tsutsui, N.; Ishii, K.; Takagi, Y.; Watanabe, T.; Nagasawa, H. Zool. Sci. 1999, 16,616

(25) Lakshminarayanan, R.; Loh, X. J.; Gayathri, S.; Sindhu, S.; Banerjee, Y.; Kini, R. M.; Valiyaveettil, S. Biomacromolecules 2006, 7 (11), 3202. 
The later identified in chicken eggshells are composed of ovotransferrin, ${ }^{27}$ ovalbumin, ${ }^{28}$ and lysozyme. ${ }^{1}$

The calcification process occurs in the uterine fluid of the oviduct, an acellular milieu that is supersaturated with $\mathrm{Ca}^{2+}$ and $\mathrm{HCO}_{3}{ }^{-}$as well as the organic precursor of the eggshell matrix. ${ }^{27,29}$ Mineral deposition takes place in three stages: initial nucleation, growth, and inhibition of growth. ${ }^{29}$ The uterine fluid collected in each stage of shell formation shows that lysozyme is particularly abundant during the initial stage of shell formation. ${ }^{27}$ One indication that shell calcification may be controlled by lysozyme is that the concentration of the protein in the uterine fluid changes at different stages of shell formation. The key question therefore concerns the role of lysozyme in the calcification process. To date, the implication of lysozyme are unclear, ${ }^{1}$ and there are only a few qualitative ideas ${ }^{31}$ about it.

Lakshminarayanan et al. ${ }^{25}$ reports that amorphous calcium carbonate could be the initial phase formed in eggshell calcification but without the implication of lysozyme. First, this result is based on images of the calcified quail eggshell that indicate that the mammilary layer (the first layer formed during eggshell formation) consists of closely assembled nanoparticles. Second, the ACC precursor phase is obtained during in vitro experiments in the presence of soluble organic matrices extracted from quail eggshell but not in the presence of lysozyme. Nevertheless, lysozyme being present in the eggshell matrix during the first stage of shell formation may influence the precipitation of ACC particles in vivo. This is the motivation for the present study of the influence of lysozyme on ACC during in vitro experiments. Moreover, the Ly-ACC transition to calcite is studied in order to understand the lysozyme functional properties during eggshell biomineralization.

\section{Experimental Procedures}

2.1. Material Preparation. Dimethyl carbonate (DMC, purity $>98 \%$ ), calcium chloride dihydrate (purity $>99 \%$ ), and sodium hydroxide (purity 99\%) were purchased from Sigma-Aldrich and used without further purification. Lysozyme was purchased from Aldrich (purity $95 \%, \mathrm{IP}=11.35, \mathrm{M}=14 \mathrm{kDa}$ ). Purified water with an electrical conductivity of less than $10^{-6} \mathrm{~S} \cdot \mathrm{m}^{-1}$ was taken from a Millipore Milli-Q system.

The preparation of amorphous calcium carbonate was performed according to the method reported by Faatz et al., ${ }^{30}$ and the reactions implicated are the following:

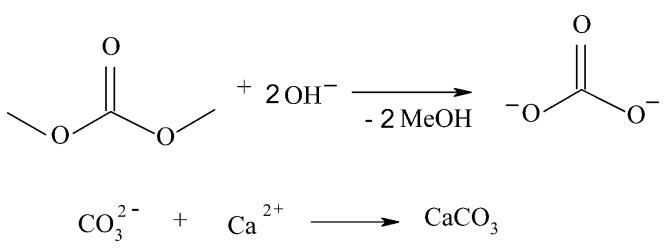

Method 1. The aqueous solution was prepared in a $100 \mathrm{~mL}$ flask containing $147 \mathrm{mg}$ of $\mathrm{CaCl}_{2} \cdot 2 \mathrm{H}_{2} \mathrm{O}(0.001 \mathrm{~mol}), 450 \mathrm{mg}$ of dimethyl carbonate $(0.005 \mathrm{~mol})$, and $0-5 \mathrm{~g} / \mathrm{L}$ protein and diluted to $100 \mathrm{~mL}$ with water. The reaction was started by adding $20 \mathrm{~mL}$ of $0.5 \mathrm{M}$ $\mathrm{NaOH}$ to a stirred reaction mixture. The initial $\mathrm{pH}$ of the solutions was $12.6 \pm 0.1$

(26) Nys, Y.; Gautron, J.; Garcia-Ruiz, J. M.; Hincke, M. T. C. R. Palevol 2004, 3, 549 .

(27) Nys, Y.; Hincke, M. T.; Arias, J. L.; Garcia-Ruiz, J. M.; Solomon, S. E. Poult. Avian Biol. Rev., in press.

(28) Hincke, M. T. Connect. Tissue Res. 1995, 31, 227.

(29) Gautron, J.; Hincke, M. T.; Nys, Y. Connect. Tissue Res. 1997, 36, 195

(30) Faatz, M.; Gröhn, F.; Wegner, G. Adv. Mater. 2004, 16, 996.

(31) Nys, Y.; Gautron, J.; Garcia-Ruiz, J. M.; Hincke, M. T. World's Poult. Sci. J. 2001, 57, 401.
Method $2.147 \mathrm{mg}$ of $\mathrm{CaCl}_{2} \cdot 2 \mathrm{H}_{2} \mathrm{O}(0.001 \mathrm{~mol}), 90 \mathrm{mg}$ of dimethyl carbonate $(0.001 \mathrm{~mol})$, and $1 \mathrm{~g} / \mathrm{L}$ lysozyme were dissolved in $\sim 98$ $\mathrm{mL}$ of water. The reaction was started by adding $2 \mathrm{~mL}$ of $1 \mathrm{M} \mathrm{NaOH}$ to a stirred reaction mixture. The initial $\mathrm{pH}$ of the solutions is 12.3 \pm 0.1 .

The $\mathrm{pH}$ of the aqueous solutions was measured using an $\mathrm{Ag} / \mathrm{AgCl}$ plastic-body electrode (TPS, model smart CHEM-Lab) and a Consort $\mathrm{C} 835 \mathrm{pH}$ meter. The solutions were stirred for $1 \mathrm{~min}$ and then left under static conditions. Afterward, the precipitate was either collected when the first signs of turbidity were observed or left in its mother liquor for $24 \mathrm{~h}$. The precipitate was removed from the solutions by filtration using $0.65 \mu \mathrm{m}$ membrane filters (MCE Mf-Millipore filters purchased from Fisher Scientific). The powders were collected and washed several times with water and acetone. Experiments were conducted at ambient temperature $\left(20^{\circ} \mathrm{C}\right)$.

2.2. Analytical Methods. 2.2.1. Particle Characterization. Fieldemission scanning electron microscopy (FE-SEM) was performed using a microscope (Hitachi, model S4500) operating at $0.5-30 \mathrm{kV}$. It has "upper and lower" secondary electron detectors (Robinson, model Mk 6). The upper detector collects $\mathrm{SE}_{1}$ secondary electrons (generated by the primary electrons; they are known to deliver the high-resolution signal) and $\mathrm{SE}_{2}$ secondary electrons (generated by the backscattered electrons), whereas the lower detector collects only $\mathrm{SE}_{3}$ secondary electrons (generated by the collision of the backscattered electrons with the chamber) and is, in practice, a backscattered electron detector. The upper detector gives better resolution than does the lower detector. The samples were coated with $\mathrm{Au} / \mathrm{Pd}$ in an Emitech sputter coater using a rotational stage.

Transmission electron microscopy (TEM) was carried out on a $300 \mathrm{kV}$ TEM from Philips (model EM 430). It is equipped with a TVIPS CCD camera (1024 pixels $\times 1024$ pixels) and an ultrathin window Oxford ISIS EDXA with element mapping.

$\mathrm{X}$-ray diffraction (XRD) measurements were made using a STOE STADI $\mathrm{P}$ diffractometer (STOE\&CIE) providing $\mathrm{Cu} \mathrm{K} \alpha_{1}$ radiation monochromated with a germanium single crystal $(\lambda=1.540598 \AA)$. Typical diffraction patterns were recorded in the range of $8^{\circ}<\theta$ $<90^{\circ}$ at a scanning speed of $0.8 \% \mathrm{~min}$.

2.2.2. Techniques Used to Study the Lysozyme-Calcium Interaction. Elemental analysis was carried out using a vario EL III elemental analyzer (Elementar Analysensysteme $\mathrm{GmbH}$ ), which yielded the amounts of CHNOS in the samples.

Dynamic light scattering (DLS) measurements were made using a Zetasizer spectrometer (Malvern Instruments Ltd., model Z3000) equipped with a $5 \mathrm{~mW} \mathrm{He}-\mathrm{Ne}$ laser. Measurements were carried out at a scattering angle of $90^{\circ}$, and the intensity autocorrelation functions were analyzed using Contin software. Before lightscattering measurements were performed, the solutions were filtered through a $2.2 \mu \mathrm{m}$ membrane filter.

Electrospray mass spectrometry (ES-MS) was carried out using a Thermoquest Finnigan TSQ 7000 (San Jose, CA) with a triplestage quadrupole mass spectrometer. The solutions were sprayed through a stainless steel capillary held at $4 \mathrm{kV}$, generating multiply charged ions. Data were collected using Xcalibur software. The instrument is calibrated using myoglobin and has an error of $0.2 \mathrm{Th}$. ES-MS was employed to study the affinity of calcium to lysozyme molecules at $\mathrm{pH} 4$.

Fourier transform infrared spectroscopy (FTIR) was recorded on a Jasco FT-IR-610 spectrometer. The samples were mixed with $\mathrm{KBr}$ powder. Subsequently, the resulting mixture was grinded for 3-5 min in an agate mortar and deposited on the sample holder. The spectra were recorded in reflection mode from 4000 to $400 \mathrm{~cm}^{-1}$ at a resolution of $2 \mathrm{~cm}^{-1}$. For the reaction kinetic experiment, an ATR accessory was used. The ATR crystal is of a trapezoid shape and is $80 \mathrm{~mm}$ long, $10 \mathrm{~mm}$ wide, and $4 \mathrm{~mm}$ thick. This accessory is available for the analysis of liquids, and it was used to monitor the transition of Ly-ACC to calcite crystals.

\section{Results and Discussion}

3.1. Influence of Lysozyme on the Metastable Form of Calcium Carbonate. In previous studies, it was shown that 

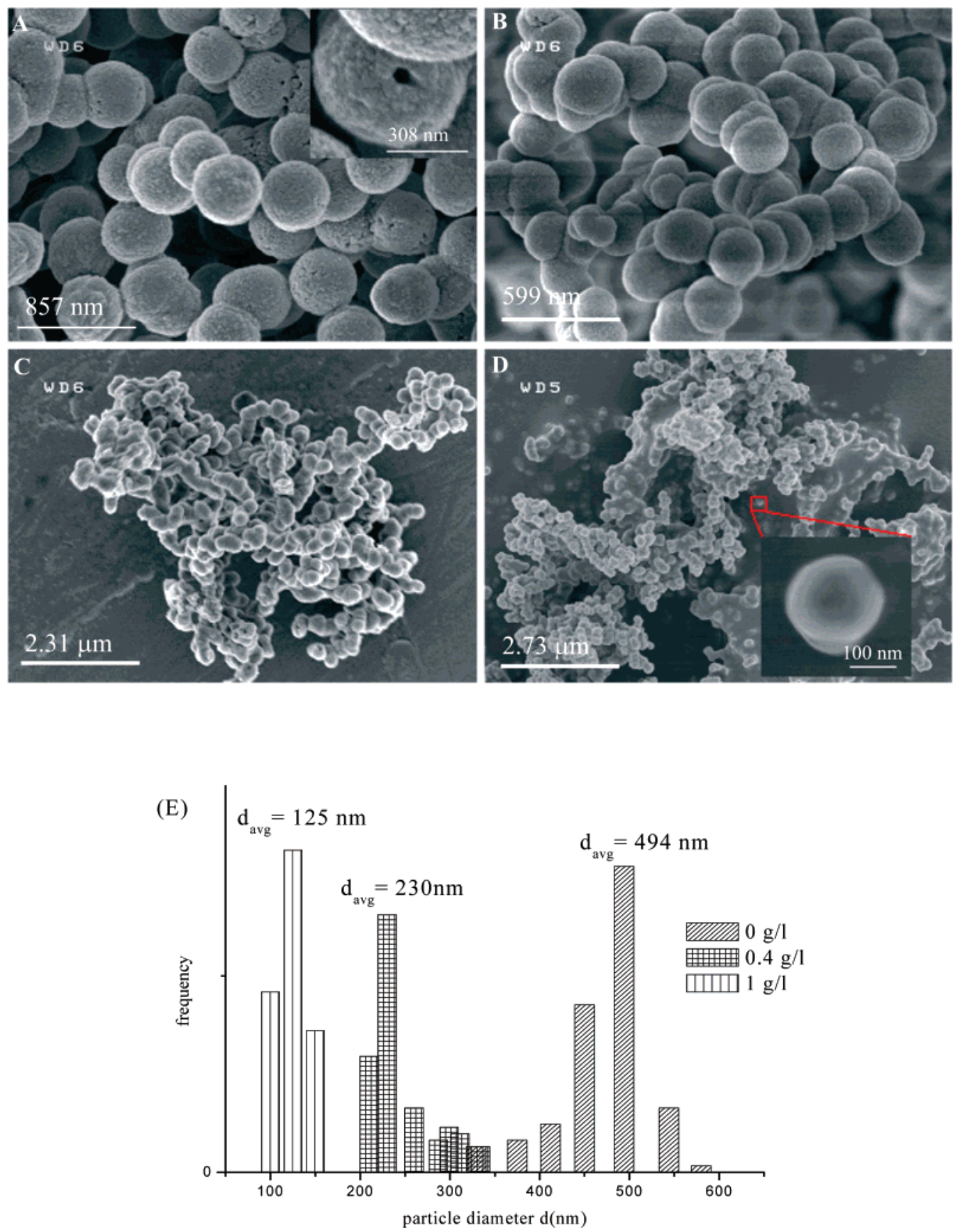

Figure 1. FE-SEM images of calcium carbonate obtained in aqueous solutions in the presence of different lysozyme concentrations: (A) 0 , (B) 0.4 , (C) 0.7 , and (D) $1 \mathrm{~g} / \mathrm{L}$. (E) Histograms of $\mathrm{CaCO}_{3}$ particle size distributions as a function of lysozyme concentration based on FE-SEM images.

lysozyme is detected in the non-calcified shell membranes and in the mammillary cone layer. ${ }^{1}$ The mammilary core zone is situated at the interface between the noncalcified and the calcified cone layer $^{31}$ (Figure $\mathrm{S}_{1}$, Supporting Information). The mammilary core consists of organic material, and it represents the place where the biomineralization process is initiated. Because lysozyme is presented at very high concentration in the mammalian cartilage, we assume that it should interfere at the onset of the eggshell calcification process and modifies the growth morphology of the particles. Therefore, the $\mathrm{CaCO}_{3}$ precipitation during in vitro experiments was performed in the presence of egg white lysozyme.

Figure 1 shows FE-SEM images of calcium carbonate synthesized in aqueous solution in the presence of different lysozyme concentrations (method 1). In a control experiment without lysozyme, amorphous calcium carbonate particles 400-
$600 \mathrm{~nm}$ in diameter (as reported by Faatz et al. ${ }^{30}$ ) were formed when the precipitate was isolated from the solution after 2 min (Figure $1 \mathrm{~A}$ ). It is interesting that the obtained ACC particles are highly spherical, not interconnected (Figure $2 \mathrm{~A}$ ), and reveal uniform holes (not reported by Faatz et al. ${ }^{30}$ ) with diameters ranging from 50 to $90 \mathrm{~nm}$ (Figure 1a inset). Xu et al. also detected holes in spherical $\mathrm{CaCO}_{3}$ particles in the presence of phytic acid. $^{32}$

The presence of lysozyme during the calcium carbonate precipitation process also led to the formation of spherical particles, but with considerable changes. The particle size depended on the lysozyme concentration (e.g., the size of the particles in solution containing $1 \mathrm{~g} / \mathrm{L}$ protein was roughly one-

(32) Xu, A.; Yu. Q.; Dong, W.; Antonietti, M.; Cölfen, H. Adv. Mater. 2005, $17,2217$. 

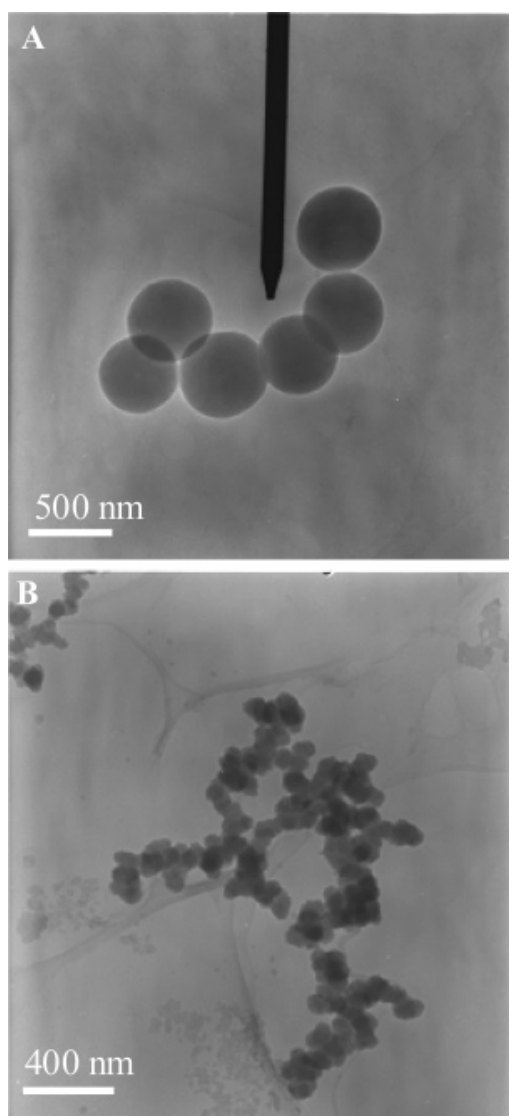

Figure 2. TEM images of (A) ACC grown in the control experiment (i.e., in a lysozyme-free solution) and (B) Ly-ACC particles synthesized in $2 \mathrm{~g} / \mathrm{L}$ lysozyme solution.

quarter of that found in the control experiment without organic additives). In some cases, these nanoparticles were aggregated and were also embedded in a faint network (Figure 1B). The degree of interconnectivity increases with lysozyme concentration (Figure 1C,D). In a previous study, it was reported that lysozyme also directs the formation of interconnected nanoparticles of silica or titania. ${ }^{33}$

The FE-SEM images were interpreted in terms of histograms of the $\mathrm{CaCO}_{3}$ particle size distribution depending on lysozyme concentration (Figure 1E). The size distribution of the control experiment, without lysozyme, was broad, with a maximum at a diameter of ca. $500 \mathrm{~nm}$. At lower lysozyme concentration, the size distribution was roughly bimodal. At higher protein concentration, the size distribution became monomodal and narrow. Mean diameters obtained for the samples containing 0.4 and $1 \mathrm{~g} / \mathrm{L}$ lysozyme are 230 and $125 \mathrm{~nm}$, respectively. As the lysozyme concentration was further increased ( $>2 \mathrm{~g} / \mathrm{L})$, the LyACC particle sizes were reduced even more. However, contrary to the case described above, where the particles were more dissociated, the Ly-ACC nanoparticles were more strongly interconnected (Figure $2 \mathrm{~B}$ ) and had a more sintered appearance at higher lysozyme concentrations.

Figure 3 presents an XRD diffraction pattern recorded for the Ly-ACC particles synthesized in $1 \mathrm{~g} / \mathrm{L}$ lysozyme solutions. The lack of distinct diffraction peaks shows that the material is amorphous.

The effect of lysozyme on the particle size is in agreement with previous observations, ${ }^{1}$ where calcite crystals were grown in the presence of purified hen lysozyme. The lysozyme

(33) Luckarift, H. R.; Dickerson, M. B.; Sandhage, K. H.; Spain, J. C. Small 2006, 2, 640

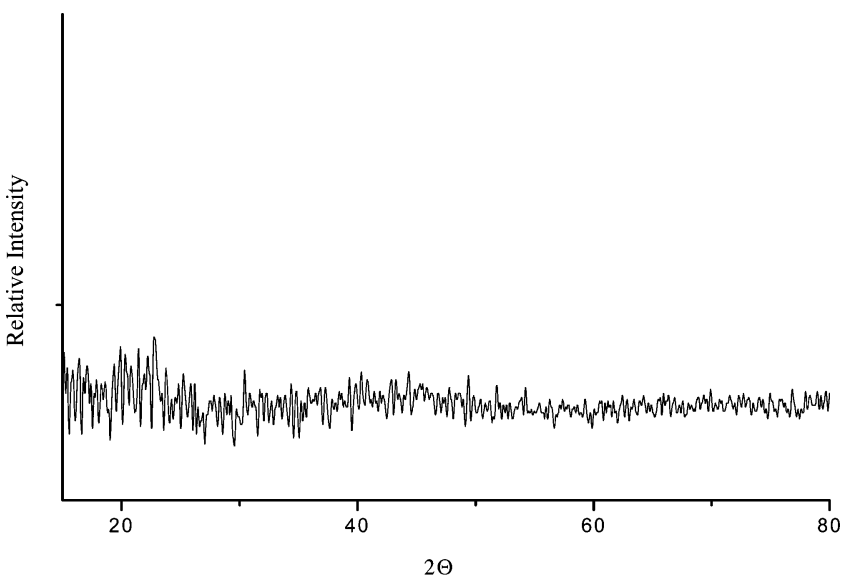

Figure 3. XRD pattern of Ly-ACC particles obtained in the presence of $1 \mathrm{~g} / \mathrm{L}$ lysozyme and collected after $2 \mathrm{~min}$.

molecules, in the calcite-growth solution, reduced the size of the crystals. This effect was also proportional to the lysozyme concentration.

At the onset of precipitation, we observe that lysozyme influences the size and the association phenomenon of the particles, whereas the amorphous nature of calcium carbonate is preserved (Figure 3). Nevertheless, lysozyme changes the chemical composition of the particles. Elementary analysis shows the presence of nitrogen in the powder. Because of this finding, the interaction between calcium carbonate and lysozyme was investigated in more detail (Supporting Information).

As a result, we assume that lysozyme creates a local distribution of calcium ions, which can play the role of calcium carbonate nucleation sites. At high $\mathrm{Ca}^{2+} / \mathrm{Ly}$ molar ratios (360/1), calcium carbonate nucleates on the few lysozyme particles and produces large objects. At lower calcium to lysozyme molar ratios (72/1), many nucleation centers exist, leading to many small particles of $\mathrm{CaCO}_{3}$ that form a network. This is a confirmation of the ionotropic effect (electrostatic accumulation). ${ }^{34}$ This effect influences the interaction and recognition process between organic and inorganic phases.

3.2. Aging of the Ly-ACC Particles. 3.2.1. Ly-ACC Nucleation and Lifetime and Its Transformation to the Calcite Phase during the First Hour after Reactant Mixing. Generally, amorphous calcium carbonate transforms into a crystalline phase by a dissolution- recrystallization ${ }^{35}$ process in solution, ACC transforms into the corresponding crystalline form when it is in contact with the master solutions. It has been shown that during the precipitation of the ACC phase the calcium ion concentration in solution decreased, followed by an increase in calcium ion concentration due to the redissolution of ACC. ${ }^{36}$ In the end, the $\mathrm{Ca}^{2+}$ concentration decreased again during calcite crystallization.

Then, the Ly-ACC nucleation, lifetime, and phase transformation to calcite polymorph in solution were monitored over time using FTIR measurements. We prepared the solution according to method 2 , in which the induction time (the time elapsed to observe the first crystal) is significantly higher $(\sim 7$ $\mathrm{min}$ ) than for method $1(\sim 2 \mathrm{~min})$. Thus, the reactions take place on a time scale ideally suited for infrared experiments. We note that the changes in $\mathrm{NaOH}$ and DMC concentrations had no effect on particle size and morphology.

FTIR spectra of the $\mathrm{CaCO}_{3}$ solution were interpreted in the range of $700 \mathrm{~cm}^{-1} \leq v \leq 1700 \mathrm{~cm}^{-1}$ in which the most important

(34) Mann, S. Nature 1988, 332, 119

(35) Sawada, K. Pure Appl. Chem. 1997, 69, 921

(36) Jimenez-Lopez, C.; Rodriguez-Navarro, A.; Domingues-Vera, J.; GarciaRuiz, J. M. Geochim. Cosmochim. Acta 2003, 67, 1667. 


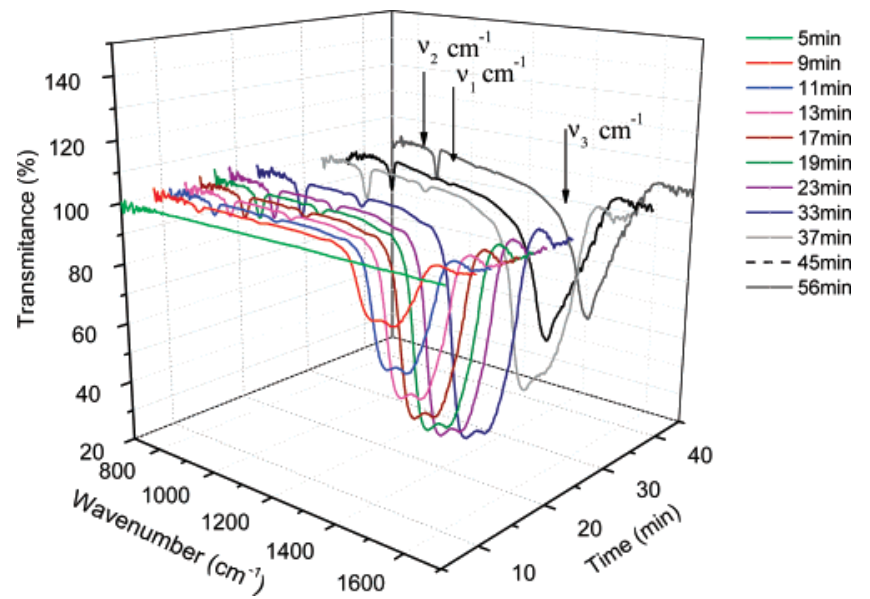

Figure 4. FTIR spectra of the $\mathrm{CaCO}_{3}$ solution at various intervals after the rapid mixing of the reactants.

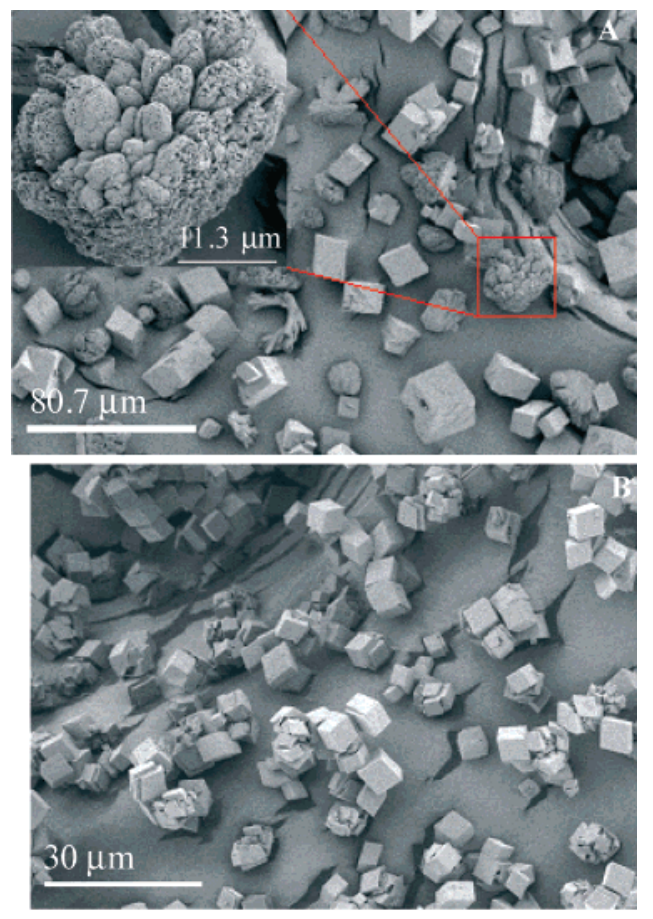

Figure 5. FE-SEM images of $\mathrm{CaCO}_{3}$ crystals synthesized in the absence (A) and in the presence (B) of $1 \mathrm{~g} / \mathrm{L}$ lysozyme. The precipitates were in contact with the mother liquor for $24 \mathrm{~h}$.

absorption bands of calcium carbonate appear (Figure 4). Although the spectrum after 5 min had no absorption bands, after $7 \mathrm{~min}$, the spectrum exhibited bands characteristic of ACC: the symmetric stretch $\left(v_{1}\right)$ at $1077 \mathrm{~cm}^{-1}$, the carbonate out-ofplane bending absorption at around $864 \mathrm{~cm}^{-1}\left(v_{2}\right)$, and a pair of split peaks at 1418 and $1480 \mathrm{~cm}^{-1}\left(v_{3}\right)$. Between 7 and $56 \mathrm{~min}$, many changes in the characteristic absorption bands took place: the $v_{1}$ absorption band disappeared; the $v_{2}$ band intensity increased, its peak shifted from 864 to $874 \mathrm{~cm}^{-1}$, and it became narrower; and the double peaks $\left(v_{3}\right)$ changed to a broad band at $1412 \mathrm{~cm}^{-1}$. All of these changes indicate the transition of LyACC to the calcite phase exclusively.

3.2.2. Amorphous Precipitate in Contact with the Mother Liquor for $24 \mathrm{~h}$. In the control experiment without lysozyme, the ACC precipitate left in contact with the aqueous solution for 24 $\mathrm{h}$ favors the formation of various $\mathrm{CaCO}_{3}$ crystal polymorphs and morphologies (Figures 5A and 6A. Thus, different types of morphologies, such as cauliflower-like (vaterite) calcium carbonate, spherical microparticles (vaterite), rhombohedral-like

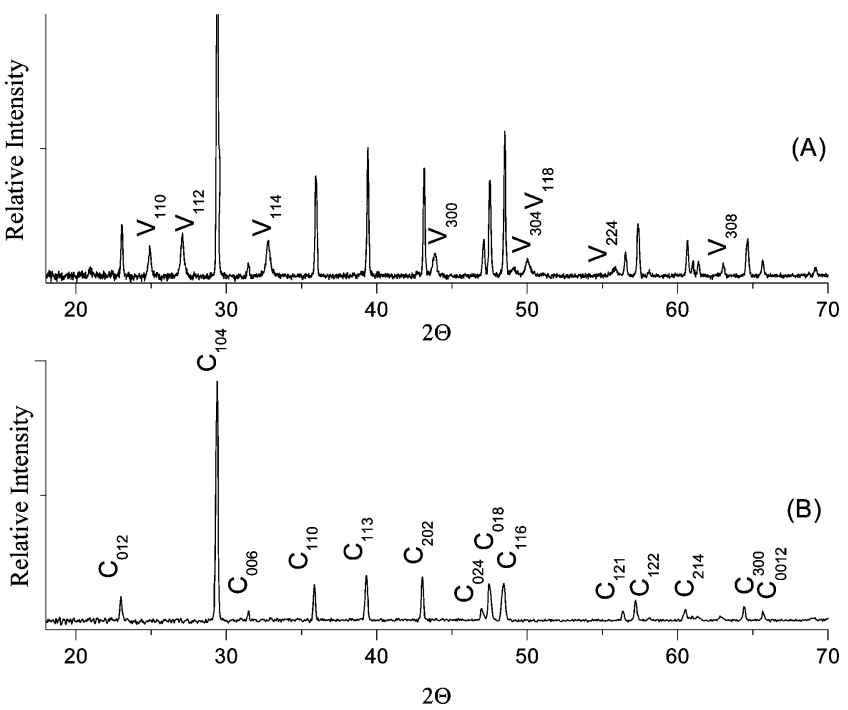

Figure 6. XRD pattern of $\mathrm{CaCO}_{3}$ particles obtained in the absence (A) and in the presence (B) of $1 \mathrm{~g} / \mathrm{L}$ lysozyme and collected after $24 \mathrm{~h}$. $\mathrm{V}$ and $\mathrm{C}$ denote peaks from vaterite and calcite, respectively.

particles (calcite), and dendrite (aragonite), were obtained. The cauliflower-like morphology is composed of lateral projections (extensions) that grow from the center with a size dispersion of around $3 \mu \mathrm{m}$ in diameter and $5 \mu \mathrm{m}$ in length. Counting the particles in the SEM micrograph shows that the sample is composed of $73 \%$ calcite, $25.1 \%$ vaterite, and $1.9 \%$ aragonite. The corresponding XRD spectrum (Figure $6 \mathrm{~A}$ ) exhibits characteristic reflections of vaterite $\left(\mathrm{V}_{110}, \mathrm{~V}_{112}\right.$, and $\left.\mathrm{V}_{114}\right)$ and calcite $\left(\mathrm{C}_{104}\right)$ but no peaks characteristic of aragonite. The lack of aragonite peaks is certainly owing to its low mass percentage, which is below the detection limit of the X-ray diffractometer. By contrast, the overgrowth of Ly-ACC particles furnished $100 \%$ calcite crystals with no other contamination (Figures 5B and 6B), and the particle size is roughly one-half $(\sim 9 \mu \mathrm{m})$ of those in the control experiment without organic additives $(\sim 20 \mu \mathrm{m})$. These results indicate that the organic additive considerably inhibited the crystal growth and favored the formation of the calcite crystalline form. The calcite crystals were aggregated and partially adopted a predominant random coil conformation.

Earlier studies confirm that lysozyme also modifies the morphology of calcite crystals, ${ }^{1,36}$ which preferentially interacted with faces parallel to the $c$ axis. ${ }^{36}$ Besides, another protein from the goose eggshell matrix (ansocalcin) used as a reaction medium for $\mathrm{CaCO}_{3}$ nucleates also aggregates from modified calcite crystals during in vitro mineralization experiments. ${ }^{37}$ However, in those studies the rhombohedral calcite crystals were observed in the absence of protein. Therefore, the influence of lysozyme on a possible favoring of the calcite phase could not be detected. By contrast, in our systems without lysozyme all kinds of morphologies are found, and only in the presence of lysozyme is pure calcite formed.

It is interesting that during the eggshell biomineralization, the calcite phase is also privileged. ${ }^{38}$ Calcite crystals found in the chicken eggshell exhibit a preferential orientation with their $c$ axes perpendicular to the surface of the shell. ${ }^{39}$

(37) Lakshminarayanan, R.; Kini, R. M.; Valiyaveettil, S. Proc. Natl. Acad. Sci. U.S.A. 2002, 99, 5155

(38) Nys, Y.; Gautron, J.; McKee, M. D.; Garcia-Ruiz, J. M.; Hincke, M. T. World's Poult. Sci. J. 2001, 57, 401.

(39) Hamilton, R. M. G. Food Microstruct. 1986, 5, 99. 
Our observations of the calcite polymorph are in accordance with observations made by Gautron et al., ${ }^{40}$ who studied the influence of uterine fluid on calcium carbonate crystal growth. The uterine fluid is the liquid surrounding the egg during formation. It contains the organic precursor of eggshell matrix proteins (i.e., lysozyme) and minerals. In the absence of uterine fluid, the crystal polymorphs were distributed as following: $55 \%$ calcite, $22.5 \%$ aragonite, and $22.5 \%$ vaterite. The presence of uterine fluid during $\mathrm{CaCO}_{3}$ precipitation drastically modified the kinetics and the total number of crystals and induced the formation of only the calcite polymorph, so in some respects, uterine fluid behaves similarly to a lysozyme solution used as a precipitation medium.

\section{Conclusions}

This article reports the influence of lysozyme on the calcium carbonate mineralization process. From our experimental results, the following conclusions can be drawn:

(1) Lysozyme considerably decreases the average diameter of the metastable amorphous calcium carbonate particles and promotes a network of associated particles. Moreover, this protein is incorporated in (or on) the precipitate.

(2) We assume that lysozyme attracts calcium ions and creates a local distribution of calcium ions that can play the role of

(40) Gautron, J.; Rodriquez-Navarro, A. B.; Gomez-Morales, J.; HernandezHernandez, M. A.; Dunn, I. C.; Bain, M.; Garcia-Ruiz, J. M.; Nys, Y. Evidence for the Implication of Chicken Eggshell Matrix Proteins in the Process of Shell Mineralization; Proceeding of the 9th International Symposium on Biomineralization (Biom 09), Pucon, Chile, 2005. calcium carbonate nucleation sites. At high $\mathrm{Ca}^{2+} / \mathrm{Ly}$ molar ratios, large individual objects (however, still smaller than in the absence of lysozyme) are formed, whereas at lower $\mathrm{Ca}^{2+} / \mathrm{Ly}$ molar ratios many small interconnected particles are formed.

(3) When the precipitate is left in the solution for $24 \mathrm{~h}$, the Ly-ACC particles reorganize exclusively into crystalline calcite. No other morphologies are found. Furthermore, the presence of lysozyme molecules has also a strong effect on the kinetics of $\mathrm{CaCO}_{3}$ precipitation.

(4) Taking into account that lysozyme is present during the eggshell biomineralization process, it is probable that lysozyme also interferes in vivo.

Acknowledgment. We thank M. Faatz, Dr. F. Gröhn, and Professor Dr. G. Wegner, Max Planck Institute (Mainz, Germany), for helpful discussions concerning the formation of ACC. We acknowledge Dr. J. Gautron, INRA (Tours, France), for his comments and advice regarding the biological part of the article. We are grateful to Dr. A. Larsson, ANU (Australia) and J. Kiermaier and W. Krutina, University of Regensburg (Germany), for recording the TEM images, making ES-MS measurements, and conducting elemental analyses, respectively.

Supporting Information Available: Calcareous structure of the chicken eggshell and the lysozyme-calcium interaction. This material is available free of charge via the Internet at http://pubs.acs.org. 